\title{
El papel del Estado y la calidad del sector público
}

\section{Vito Tanzi}

Director,

Departamento de Asuntos Fiscales,

Fondo Monetario Internacional vtanzi@imf.org
Este artículo llega a la conclusión de que la calidad del sector público sólo puede evaluarse en relación con el papel del Estado. En general, un sector público eficiente debería poder alcanzar los objetivos del Estado, con la menor distorsión posible del mercado, con la carga tributaria más baja posible sobre los contribuyentes, con el menor número posible de empleados públicos y con la menor absorción posible de recursos económicos por el aparato público. Los procesos y resultados del sector público deben ser transparentes. La corrupción no debería desempeñar papel alguno en las decisiones de los burócratas y de los dirigentes políticos. Y los recursos en manos del sector público deberían dedicarse a usos que maximicen su rentabilidad social. La calidad del sector público también es importante para alcanzar el objetivo de equidad que hoy se percibe como una de las metas fundamentales del Estado. Un sector público de alta calidad permitiría ir tras la equidad con costos menores en términos de eficiencia. Finalmente, las llamadas reformas de primera generación no siempre elevan la calidad de este sector, aunque sí mejoran la de la política pública. De hecho, el ir en pos de reformas de primera generación es lo que ha puesto de relieve la necesidad de mejorar la calidad del sector público. Para que esto último se logre, son necesarias las reformas de segunda generación. 


\title{
I \\ El papel del Estado
}

\author{
“Cuál es el mejor gobierno? \\ Aquel que nos enseña a gobernarnos \\ a nosotros mismos" \\ Johann Wolfgang von Goethe
}

Los seres humanos son animales sociales y, en consecuencia, tienden a congregarse en grupos. Esa congregación genera mercados y crea la necesidad de instituciones sociales. Los mercados y las actividades económicas se caracterizan por la especialización entre los participantes. La especialización lleva al intercambio, lo que a su vez supone contratos. Estos pueden ser implícitos o explícitos. Los contratos implícitos caracterizan a las sociedades primitivas y a menudo se imponen por la aplicación de códigos morales y sociales. A medida que se desarrolla, la sociedad exige contratos más explícitos o formales. Ellos, por su parte, demandan instituciones que los registren, cuando se exija su registro, y que los hagan cumplir. En las economías de mercado, los individuos también acumulan activos y esta acumulación lleva a la necesidad de proteger la propiedad. Además, necesitan protección contra los elementos criminales dentro de sus propios grupos o de fuentes foráneas. Así, todo conglomerado de individuos exige la existencia de instituciones, por rudimentarias que sean, que cumplan estas funciones y que puedan considerarse como un Estado mínimo. Este es el papel esencial del Estado en una sociedad primitiva o su papel mínimo en cualquier sociedad. ${ }^{1}$

$\square$ El presente artículo pretende ser un aporte a la literatura sobre las reformas de segunda generación. Una versión anterior fue presentada a la Conferencia sobre reformas de segunda generación organizada por el Fondo Monetario Internacional (Washington, D.C., 8 y 9 de noviembre de 1999) y a otra sobre el control de las actividades públicas organizada por el Banco de Italia (Perugia, 2 y 3 de diciembre de 1999). El autor agradece los comentarios sobre una versión preliminar de este informe que le hicieron llegar Era Dable-Norris, Barry Potter y Howell Zee. También expresa su agradecimiento a Patricio Castro, Jerome Fournel, Eduardo Ley, Istvan Székely y otros participantes de un seminario interno del Departamento de Finanzas Públicas del FMI. Las opiniones vertidas en este artículo son estrictamente personales y no deben interpretarse como una posición oficial del Fondo Monetario Internacional.

${ }^{1}$ Existe una extensa bibliografía en apoyo de la tesis de que incluso las pandillas o asociaciones de criminales exigen alguna organización interna que representa una forma rudimentaria de gobierno. Véase Skaperdas y Syropoulos (1995), Charap y Harm (por publicarse) y varios estudios en Fiorentini y Zamagni (eds. 1999). El concepto de Estado mínimo o incluso ultramínimo se analiza en Nozick (1974).
A medida que las sociedades se vuelven más complejas, y los grupos que las integran se hacen más grandes y menos homogéneos, el Estado debe ir asumiendo nuevas responsabilidades si desea promover plenamente el bienestar de los individuos que las componen. Por ejemplo, los mercados no resultan eficientes cuando los distorsionan los monopolios o cuando la información esencial no está al alcance de los participantes, o resulta demasiado onerosa para que puedan acceder a ella. Se plantea entonces la necesidad de que el Estado regule los mercados y proporcione un mínimo de información esencial a la población. De ahí que deban crearse instituciones para satisfacer esas necesidades (Banco Mundial, 1997).

Hay algunos bienes (defensa, calles, etc.) que sólo el Estado puede proporcionar porque los individuos no tendrían ningún interés en hacerlo. Una razón importante es que una vez que se proporcionan estos bienes, el proveedor no puede excluir de su usufructo a los individuos que no quieren contribuir a costearlos. Por otra parte, una vez que se han proporcionado, pueden ser consumidos por todos, de modo que resulta ineficiente para una sociedad en su conjunto excluir a algunos de su consumo. Siendo así, cuando los bienes son esenciales, deben ser provistos (pero no necesariamente producidos) por el Estado. Se trata de los bienes públicos de los que habla la literatura económica. Asimismo, la producción o el consumo de algunos bienes o actividades genera externalidades positivas o negativas que no aprovechan quienes los consumen o producen. De no intervenir el Estado, el mercado registrará una sobreproducción o subproducción de esos bienes o actividades. Nuevamente puede ser necesaria la intervención del sector público. ${ }^{2}$

Todos los ejemplos anteriores corresponden al papel general del Estado, a lo que en la literatura eco-

\footnotetext{
2 Tradicionalmente la intervención del Estado se traduce en crear impuestos para generar externalidades negativas y subvencionar a aquellos que generan externalidades positivas.
} 
nómica sobre el sector público se denomina asignación de recursos (véase Musgrave, 1959). Aunque algunos problemas de la asignación de recursos pueden resolverse recurriendo a la reglamentación, a menudo el Estado necesita recursos para poder cumplir esta tarea. En principio, el Estado podría apropiarse directamente de estos recursos obligando a los individuos a contribuir su tiempo o su riqueza para la producción de los bienes requeridos - como lo hace, por ejemplo, con el servicio militar obligatorio o algunas modalidades de expropiación. En épocas medievales a menudo se construían caminos con este sistema. Sin embargo, la solución más eficiente es la de aplicar fondos obtenidos por la tributación. Se plantea entonces la necesidad de contar con un sistema tributario y un andamiaje institucional para recaudar los impuestos. Y, por supuesto, debe haber instituciones que gasten el dinero y lleven la contabilidad de su uso. En todas estas actividades, en una economía de mercado se espera que el Estado minimice su costo para el mercado y la sociedad en su conjunto. Por lo tanto, un sector público de elevada calidad debe descansar en un sistema tributario eficiente y un sistema de egresos que minimice el gasto ineficiente e improductivo. También exige un presupuesto suficientemente amplio como para que el Estado pueda cumplir su misión en forma satisfactoria (véase Tanzi y Zee, 1997).

Aparte el papel esencial o fundamental del Estado en la asignación de recursos — función que ha sido expresamente reconocida y descrita por los economistas por lo menos desde que Adam Smith publicó La riqueza de las naciones - en este siglo se le han reconocido al Estado otras dos o quizá tres funciones económicas. Ellas son las de i) redistribución del ingreso, ii) estabilización de la actividad económica, y iii) promoción del crecimiento económico y del empleo. Estas últimas tareas no están tan bien ancladas en la teoría económica como la asignación de recursos, pero fueron cobrando importancia en la aplicación práctica de la política económica en los últimos 50 años del siglo veinte. ${ }^{3}$

Los mercados producen bienes y servicios y rinden ingresos para quienes participan en ellos. Según sea la situación inicial de los individuos en cuanto propietarios de activos reales, recursos financieros, capital humano y capacidad creadora en general, y según

\footnotetext{
${ }^{3}$ Estas funciones no habían influido notablemente en el comportamiento de los gobiernos en las economías de mercado hasta el siglo XX.
}

sea el esfuerzo desplegado, la propensión al ahorro, la suerte y la disposición a afrontar el riesgo, así como la política gubernamental, se configura una modalidad determinada de distribución del ingreso (y de la riqueza). Esta distribución puede o no coincidir con el consenso societal sobre el grado de desigualdad que se considera aceptable. Además, por efecto de incapacidades físicas o mentales, u otras características o situaciones particulares, como la vejez, la cesantía, número de cargas familiares, etc., algunos individuos no podrán generar un ingreso suficiente para mantenerse a sí mismos o a sus familias. En esos casos, a partir del siglo XX y en algunos países, se ha esperado que el Estado les traspase un ingreso destinado a elevar su consumo por sobre cierto mínimo esencial. ${ }^{4}$

La atribución de una función redistributiva al Estado ha alterado fundamentalmente la naturaleza de su intervención en la economía porque ha introducido elementos u objetivos puramente políticos en su gestión. En efecto, aunque en principio el papel del Estado en la asignación de recursos debiera desprenderse exclusivamente de un análisis técnico objetivo, en la práctica no es posible definirse objetivamente el papel redistributivo adecuado del Estado. Por ejemplo, no hay método objetivo para calcular un coeficiente Gini ideal, ni la relación ideal que deba existir entre el quintil superior y el inferior de la distribución de ingresos de un país. Las decisiones sobre la materia se ven inevitablemente coloreadas por los prejuicios de los individuos que forman el gobierno en el poder.

Los programas destinados a la redistribución del ingreso a menudo exigen cuantiosos recursos e instituciones encargadas de administrarlos. Por este motivo, suelen implicar grandes incrementos del gasto público y el nivel de la tributación, como ha ocurrido en los países empeñados en el bienestar social. ${ }^{5}$ A veces se ha intentado cumplir los objetivos de redistribución aplicando una tributación progresiva. Pero con mayor frecuencia ha requerido grandes burocracias y un abultado gasto público. En muchos países gran proporción de la administración pública se dedica ahora a los servicios de educación y salud y una gran proporción del gasto fiscal de los países industriales se invierte en pro-

\footnotetext{
${ }^{4}$ En siglos anteriores los grupos religiosos cumplían una función similar de ayuda a los más pobres.

${ }^{5}$ El Banco Mundial (1997) sostiene que el proceso de asumir estas nuevas funciones ha distraído al Estado de su papel más fundamental. Schansberg (1996) afirma que la redistribución del ingreso se ha asociado frecuentemente con malas políticas que perjudican en vez de ayudar a los pobres.
} 
gramas sociales, entre ellos los de pensiones. En algunos casos, el empleo fiscal ha tenido como objetivo específico el de redistribución del ingreso (véase Alesina, Danninger y Rostagno, 1999).

Los mercados no funcionan sin altibajos; por el contrario, se caracterizan por fluctuaciones que a veces llegan a constituir verdaderas recesiones, o incluso depresiones, que se traducen en cesantía y pérdida de producción. En los últimos cincuenta años el objetivo de mantener el empleo - si no pleno por lo menos de alto nivel- y la estabilidad de la producción se ha convertido en otra justificación para la intervención del Estado. La promoción de este objetivo keynesiano está a cargo de funcionarios públicos y exige la existencia de instituciones especiales. Estos funcionarios deben tener la capacidad de cambiar el ingreso tributario y el gasto público a fin de dar la orientación adecuada a la demanda global y deben tener la información, el conocimiento técnico y la sabiduría necesarios para tomar las decisiones que convengan.

Finalmente, en los últimos decenios los gobiernos han promovido también políticas encaminadas a elevar la tasa de crecimiento o a crear empleo. Las políticas industriales y de sustitución de importaciones son ejemplos de iniciativas tendientes a elevar la tasa de crecimiento. La manipulación de la semana laboral y las inversiones públicas en determinadas actividades ilustran los intentos por elevar el empleo. Cualquiera sea la sensatez de estas políticas, tiene que haber instituciones especiales que se hagan cargo de su ejecución.

Podemos resumir el papel del Estado en una economía de mercado en la forma siguiente:

i) debe establecer y hacer cumplir reglas formales en la economía, entre ellas las que se refieren a la obligatoriedad de los contratos y la protección de los derechos de propiedad, así como también las reglas que rigen la exacción y el uso de los ingresos fiscales;

ii) debe erigir un marco jurídico y reglamentario que reduzca los costos de las transacciones -es decir, el costo de tratar con otros individuos en asuntos económicos- y debe promover la eficiencia del mercado (a través de una intervención estratégica cuando éste entre en falencia o mediante la producción de informaciones esenciales);

iii) debe proveer bienes de uso público y remediar casos evidentes de externalidades que no pueden ser resueltas por la negociación entre los intereses privados;

iv) debe promover la estabilización macroeconómica, $y$ v) debe promover una distribución del ingreso concordante con la opinión vigente de la sociedad.

Para cumplir estas funciones, el Estado necesita contar con algunos reglamentos e instituciones.

El papel del Estado ha evolucionado con el tiempo y en forma diferente en distintos países (véase Van Creveld, 1999), debido en parte a visiones cambiantes o distintas de ese papel y a la evolución de las tecnologías que afectan las posibilidades de acción estatal. Por lo tanto, la eficiencia del sector público debe valorarse a la luz de los objetivos y prioridades del gobierno en una coyuntura dada. Estos objetivos pueden variar en función de las necesidades actuales de un país en particular y a veces pueden incluso entrar en conflicto unos con otros. El Estado cumple su papel poniendo en juego una serie de reglamentos, leyes e instituciones que conforman el sector público. Cuanto más alta sea la calidad de este sector, tanto más fácil le será al Estado cumplir su cometido.

La calidad del sector público se define aquí como la característica que le permite alcanzar sus objetivos en la forma más eficiente posible. Aunque es difícil separar ambos conceptos, la calidad del sector público no coincide necesariamente con la calidad de la política económica. Por lo tanto, hay que distinguir entre la calidad del sector público y la calidad de las políticas que un gobierno determinado pueda estar aplicando en determinada coyuntura. Un sector de elevada calidad es simplemente el instrumento que facilita la formulación y ejecución de las políticas gubernamentales. Un buen sector público ayuda al gobierno a llevar adelante buenas políticas. Pero un sector público de elevada calidad no puede garantizar siempre la aplicación de buenas políticas económicas, porque no puede impedir que los gobernantes ocasionalmente persigan políticas deficientes. Sin embargo, casi no cabría calificar a un sector público como de elevada calidad si frecuentemente las políticas propuestas fueran deficientes y en cambio sí cabría esperar una gran correlación entre la calidad del sector público, según se ha definido, y la calidad de la política económica. En otras palabras, a la larga es probable que un sector público de alta calidad promueva buenas políticas y que un sector público deficiente promueva políticas erradas.

La definición de un sector público de elevada calidad que se emplea en este estudio difiere del concepto de "buen gobierno" que emplean otros autores. Por ejemplo, La Porta, López-de-Silanes, Shleifer y Vishny (1998) definen el "buen gobierno" como aquel que "be- 
neficia al desarrollo capitalista". No distinguen entre la calidad del sector público y la calidad de la política pública. Un sector público deficiente, evidentemente, hará más difícil la aplicación de una buena política por- que no proporcionará al gobierno la información necesaria y no podrá garantizar que las decisiones de política no se desvirtúen en su etapa de ejecución (sobre este particular, véase Tanzi, por publicarse).

\section{II}

\section{La importancia de las reglas}

En la sección anterior se describieron en términos generales las grandes categorías de la intervención estatal en la economía. Cada una de esas categorías exige programas específicos y cada programa debe descansar en un mandato jurídico. En las democracias con economía de mercado, el mandato de intervención estatal en la economía suele estar detallado primero en la constitución y luego en muchas leyes y reglamentos que dan un contenido específico a los principios, normalmente generales, que se asientan en la constitución. ${ }^{6}$ La constitución, las leyes y los reglamentos definen las reglas del juego que orientan la conducta de los individuos y las empresas, por una parte, y las instituciones públicas, por la otra. Sin embargo, como han señalado North y Weingast (1994, p.312), un factor político crítico es el grado de compromiso que caracteriza al régimen o mandatario frente a esas reglas. $^{7}$

\section{El papel de las constituciones}

Los principios enunciados en la constitución pueden ser claros pero a menudo no son específicos. La constitución debe ser un documento vivo que orienta la acción, pero no puede tomar en cuenta situaciones concretas ni prever actividades o situaciones que no existían en el momento de redactarla. Se cuenta que Napoleón rechazó el proyecto de constitución que los mejores juristas de su tiempo le habían preparado porque le parecía que el documento era demasiado específico y por lo tanto posiblemente resultaría demasia-

\footnotetext{
${ }^{6}$ Véase una descripción completa del papel de las instituciones jurídicas en Davis y Trebilcock (1999).

${ }^{7}$ Bajo gobiernos autoritarios o dictaduras la constitución puede tener una importancia marginal. La constitución de Stalin para la Unión Soviética era muy buena, pero no impedía que Stalin hiciera lo que le diera la gana. Evidentemente no estaba obligado por las limitaciones constitucionales.
}

do restrictivo y caducaría a poco andar. Prefería una declaración de principios generales que pudiera interpretarse con cierta flexibilidad en el futuro. En gran parte, la constitución de los Estados Unidos corresponde a este modelo. En contadas ocasiones ha requerido alguna enmienda. Además, nunca ha sido puesta en tela de juicio la autoridad de la Corte Suprema para interpretarla.

Abundan los ejemplos de principios constitucionales que no son demasiado claros. Un ejemplo bien conocido es el del artículo 81 de la constitución italiana que parece restringir el financiamiento deficitario, pero que, con los años, se ha ido interpretando de tal forma que no pudo evitar la aparición de grandes déficit fiscales (véase Martino, 1989). También abundan los casos de límites constitucionales demasiado restrictivos. Un ejemplo destacado es el de la constitución brasileña de 1988, que en años recientes ha impedido que el gobierno nacional aplique reformas importantes y muy necesarias en el sistema fiscal federal y en el sistema de pensiones. Otros tantos casos son los de la constitución india que ha impedido el establecimiento de un impuesto nacional sobre las ventas y de la constitución paquistaní que ha limitado sólo a los bienes todo impuesto sobre las ventas que quiera aplicar el gobierno nacional, excluyendo los gravámenes sobre los ingresos agrícolas (véase también Dethier y Shapiro, 1998).

Un problema que afecta a las constituciones es que tienden a reflejar las preocupaciones y fuerzas políticas predominantes en el momento en que fueron redactadas. La constitución italiana que entró en vigor en 1948 ofrece un buen ejemplo. Su primer artículo da la pauta al declarar que Italia es una república democrática basada en el trabajo. Luego entra a declarar que todos los ciudadanos tienen derecho a trabajar (artículo 4). El tercer capítulo (título III), que trata concretamente de las relaciones económicas, enumera muchos derechos de los trabajadores y sólo limitaciones a los 
derechos de propiedad de los individuos. Especifica que el Estado i) puede establecer límites sobre el uso de la propiedad; ii) puede expropiarla en el interés nacional, y iii) puede imponer diversos límites al usufructo de la propiedad a fin de establecer relaciones sociales equitativas. Un autor italiano ha contrastado esta "República de los trabajadores" con la "República de los propietarios" de la constitución anterior (véase Rodotá, 1995, p. 352).

Estas limitaciones del derecho de propiedad deben compararse con la opinión de Edmund Burke según el cual «la ley que atenta contra la propiedad es una ley contra la industria», o con la de Adam Smith que sostenía que «la adquisición de propiedades grandes y valiosas... exige el establecimiento de un gobierno civil. Cuando no hay propiedad... el gobierno civil no es tan necesario». ${ }^{8}$ Si para cumplir el papel económico que le corresponde al Estado en una economía de mercado es preciso proteger los derechos de propiedad de los individuos, como sostiene gran parte de la bibliografía reciente, ${ }^{9}$ no parece que la constitución italiana, por lo menos en sus declaraciones formales, esté bien dispuesta a asignarle este papel al Estado. No es de sorprender, por lo tanto, que las políticas económicas y las instituciones italianas se hayan desarrollado conforme a la constitución y que en ciertas ocasiones se hayan permitido políticas (control de alquileres, expropiaciones de tierras con muy baja compensación, etc.) que no se compadecen con el principio de protección de la propiedad. Esto también explicaría por qué Italia se encuentra entre los de menor puntaje, en cuanto a "libertad económica", entre los países evaluados por el Economic Freedom Network.

En conclusión, el papel que cumplen las constituciones en la determinación de la calidad del sector público en las economías de mercado democráticas modernas no puede sobreestimarse. ${ }^{10}$ La constitución es la que estimula o permite ciertas actuaciones por parte del ente gobernante y de la ciudadanía. Por lo menos en principio, la legislación y los reglamentos que rigen a un país deben acatar los principios constitucionales según los interpreta la Corte Suprema o algún organismo equivalente. En los últimos años se

\footnotetext{
${ }^{8}$ Citados ambos por Landes (1999), en pp., 32 y 33 respectivamente (traducción propia).

9 Véanse, por ejemplo, Landes (1999), North y Thomas (1973), North y Weingast (1994) y Davis y Trebilcock (1999).

${ }^{10}$ Por supuesto que se da por hecho de que la legalidad está bien asentada en el país de tal manera que la constitución se toma en serio. También se supone que existen cortes supremas eficaces. En Italia comenzó a funcionar la "corte constitucional" diez años después de aprobada la constitución (véase Rodotá,1995, p.353).
}

ha tendido en muchos países a modernizar la constitución, con resultados no siempre satisfactorios. A veces las nuevas constituciones han sido mal redactadas, y resultan complejas y confusas.

Algunos economistas, entre ellos James Buchanan y Francesco Forte, sostienen que el papel económico o fiscal que cumple la constitución debe ser el de establecer los límites de la acción gubernamental, como lo hace, por ejemplo, la constitución suiza. Según estos autores, la constitución debe señalar lo que el Estado no puede hacer y no tanto lo que debe hacer (véase Forte, ed., 1998). Estos autores abogarían, por ejemplo, por las limitaciones a las tasas impositivas, o a los niveles del gasto fiscal y los déficit fiscales. Se trata evidentemente de dar mayor capacidad de maniobra al funcionamiento del mercado. El pacto de Maastricht sobre estabilidad y crecimiento podría considerarse como un ejemplo de tales límites a la constitución.

En algunos casos - nuevamente nos acordamos del caso del Brasil- una reforma de la constitución para remover los obstáculos que se oponen a cambios aconsejables e importantes podría ser condición necesaria para mejorar la calidad del sector público y de la política pública.

\section{La legislación}

Mientras la constitución establece, o debiera establecer, las normas generales que orientan las políticas de un país, estas últimas se ven autorizadas y dirigidas por una legislación específica. Podría argumentarse que en general es mejor la calidad del sector público cuando el número de leyes es relativamente pequeño, éstas se hallan claramente redactadas $-\mathrm{y}$ por lo tanto no pueden ser objeto de interpretaciones conflictivas-, son completas y no se contradicen unas con otras. Se plantean dificultades cuando las leyes son demasiado numerosas, de redacción oscura, y no cubren todos los aspectos de la actividad económica o dan señales contradictorias.

Se ha informado que mientras algunos países europeos sólo tienen unos pocos miles de leyes en aplicación, otros tienen decenas de miles (véase Ferro, Lo Faso y Salvemini, 1999). Puede así ser difícil abrirse camino por la maraña legislativa. El sistema jurídico puede estar aquejado de un problema conceptualmente parecido al del año 2000. Ocurre porque cada vez que se dicta una nueva ley, es preciso examinar todas las demás leyes vigentes y, cuando es necesario, revisarlas para que todos sus elementos concuerden con los de la nueva ley. Este proceso, por supuesto, no ocurre. Cuando las leyes en vigor son demasiado nume- 
rosas, y especialmente cuando no son claras, es casi imposible efectuar esa verificación. Por lo tanto, elementos incorporados en leyes promulgadas en el pasado, y todavía vigentes, pueden en algún aspecto entrar en conflicto con la nueva legislación. Cuando esto sucede, se confunden las directivas que se imparten a la ciudadanía así como a las instituciones encargadas de hacer cumplir los programas previstos en esas leyes. El problema podría calificarse de incongruencia legislativa. Caracteriza a menudo las relaciones entre los gobiernos nacionales y subnacionales, o entre, por ejemplo, los programas de pensiones y salud, por un lado, y la ley del presupuesto anual, por el otro. ${ }^{11}$ Las leyes de zonificación y la legislación relativa al medio ambiente también han estado aquejadas por este problema. A veces, una ley y la institución competente autorizan determinado uso de la tierra, pero hay otra ley y otra institución que lo prohíben. Estos conflictos pueden llevar a costosas equivocaciones e inseguridad sobre los derechos de propiedad y podrían tener un efecto negativo sobre las decisiones del mercado.

Reiteramos que la calidad del sector público mejora cuando las leyes están bien redactadas y cubren todos los aspectos necesarios, cuando no se prestan para interpretaciones encontradas por parte del público o de los funcionarios gubernamentales, cuando no son más numerosas que lo estrictamente necesario y cuando no se contradicen unas con otras. En el pasado varios países -Francia, Italia, Nueva Zelandia y Rusia- han intentado o codificar las leyes existentes o simplificarlas. Sin embargo, estas iniciativas, que sólo rendirían beneficios a largo plazo, no suelen recibir gran apoyo político. Por ello, estos intentos se abandonan frecuentemente antes de que rindan los frutos esperados. $^{12}$

\section{La reglamentación}

Las leyes se complementan muchas veces con reglamentos específicos. ${ }^{13}$ Estos pueden clasificarse en tres grupos: reglamentos económicos, reglamentos de seguridad y reglamentos de información. Los reglamentos explican los procedimientos, describen el conteni-

\footnotetext{
11 Por ejemplo, la ley de presupuesto puede asignar determinada partida para el sector de la salud, pero las leyes que rigen la conducción del sector salud pueden exigir un gasto mayor. Véase Reviglio (1999) en que se da un ejemplo específico de lo que ha sucedido en Italia.

12 Véase, por ejemplo, Guy (1996), Braibant (1996), Mattarella (1994), Smith y Richardson (1999) y Tan y Tower (1992).

${ }^{13}$ Los reglamentos pueden ser legislados y constituir leyes en sí mismos, o pueden ser promulgados por otros organismos públicos.
}

do de las leyes o simplemente imponen reglas que deben acatar los individuos y las empresas. En algunos casos las leyes son tan complejas que exigen una reglamentación muy amplia. Por ejemplo, los reglamentos que rigen el código de impuestos internos de los Estados Unidos se extienden por unas 18000 páginas. El código de impuestos internos en sí mismo tiene 2300 páginas. Los reglamentos impartidos por una autoridad ejecutiva o un organismo regulador pueden ser muy complejos, no estar fácilmente al alcance del público y pueden duplicar parcialmente el contenido de otros reglamentos. En algunos países pueden estar inéditos. ${ }^{14} \mathrm{Y}$, sin embargo, como señalaba un informe reciente de la Organización de Cooperación y Desarrollo Económicos (OCDE, 1999, p. 179), la reglamentación es quizá la forma más generalizada de intervención estatal en la actividad económica.

Como muchas formas de reglamentación no exigen asignaciones presupuestarias ni aprobación oficial de la legislatura, tienden a ser menos revisadas. Por eso, a menudo hay una plétora de reglamentos y su interpretación con suma frecuencia queda en manos de los burócratas que los administran. De ahí que sea muy grande la posibilidad de confusión o abuso. La reglamentación ha sido identificada por los investigadores interesados como una de las causas principales de corrupción, porque los burócratas a cargo pueden abusar de ella para obtener algún provecho personal (véase Tanzi, 1998b). Se ha demostrado también que significan un alto costo en términos de bienestar para la economía. ${ }^{15}$

Por la naturaleza dinámica de las economías y debido a la velocidad del cambio tecnológico, no es raro encontrar en los países una abundancia de reglamentación anacrónica, inútil o hasta perjudicial y una escasez de las reglamentaciones necesarias que se relacionan con las nuevas actividades económicas. ${ }^{16}$ En esta

\footnotetext{
${ }^{14}$ En un país en que trabajé hace muchos años los reglamentos sobre incentivos tributarios no estaban disponibles para el público en ninguna forma. Los burócratas que tomaban las decisiones tenían así todos los conocimientos y sus decisiones eran inapelables para los contribuyentes. No son raros estos casos de asimetría en la disponibilidad de información entre el Estado y la ciudadanía. 15 Véase United States Congress, Senate Committee on the Budget (1984); Dixit (1996); Laffont y Tirole (1993); FIEL (1988); OCDE (1999) y Jacobs (1999).

${ }^{16}$ Hace un par de años se informó en la prensa estadounidense que en California el pan tenía que venderse en trozos de un peso exacto bien especificado. Este reglamento, que todavía estaba vigente, había sido dictado a comienzos de siglo cuando la mayoría de los compradores no tenían pesas de modo que fácilmente podían engañarlos panaderos inescrupulosos. En Italia y Alemania los descuentos en las ventas minoristas deben ser aprobados por la municipalidad y deben tener una duración limitada.
} 
área la escasez y la superfluidad a menudo coexisten. Muchos países están ahora empeñados en crear las reglamentaciones requeridas para los sectores financiero y bancario, para la nueva supercarretera de la informática (internet), para la investigación genética, para el uso de drogas y para varios otros nuevos e importantes sectores.

En resumen, un sector público de alta calidad debe tener suficientes reglas claras como para poder orientar la actividad económica (y otras), pero no tantas y tan vagas que otorguen un poder desmedido a los burócratas y creen confusión entre quienes toman las decisiones económicas. En general, las reglas deben especificar lo que no se permite más bien que autorizar lo que se permite. En lo posible el ejercicio de la discreción por parte de los burócratas debe mantenerse en un mínimo. Se sabe de países en que algunas actividades - por ejemplo, una solicitud para obtener un incentivo tributario o el permiso para establecer una pequeña empresa - necesitan el visto bueno de 30 a 40 funcionarios públicos de otras tantas organizaciones u oficinas ( véase, entre otros, De Soto, 1987). Este proceder no conduce a un sector público de alta calidad ni a un mercado eficiente.

Un paso importante sería el de preparar un inventario periódico, digamos cada diez años, de todos los reglamentos existentes, para preparar un presupuesto de reglamentaciones que pudiera podarse de los elementos redundantes o anacrónicos, injertándole los nuevos necesarios y aclarando los reglamentos confusos. Estos ensayos han tenido resultados buenos y malos en unos pocos países como Hungría y Argentina. Este proceso, aunque costoso, mejoraría la calidad general del sector público. Otra innovación útil sería la introducción del trámite único —o centro de ventanilla única - en que los interesados pudieran obtener todos los permisos y autorizaciones que necesitan para sus actividades. En unos pocos lugares se han creado estos centros, que, según parece, han llevado a la eliminación de muchas reglamentaciones en vigor y a la disminución de la corrupción. ${ }^{17}$

Aparte las reglamentaciones constitucionales formales y las disposiciones especificadas en la legislación y en los reglamentos, pueden influir en el sector público normas o disposiciones oficiosas que influyen sobre la conducta económica de los individuos y del sector público. Esas normas i) influyen sobre la elección de presidentes, ministros y otros altos funcionarios; ii) determinan los nombramientos en la administración pública, y iii) conforman los contactos entre el Estado y el sector privado. ${ }^{18}$ Pueden descansar en criterios religiosos, sociales o políticos. Como son de naturaleza oficiosa y se basan en características culturales, son difíciles de cambiar. Con todo, las relaciones impersonales y el imperio de la ley en todos los aspectos de la gestión pública deben ser la meta a que se aspirará en la búsqueda de un sector público de mejor calidad (véase Tanzi, 1995).

\section{III}

\section{Reglas políticas y de procedimiento}

La constitución, las leyes y los reglamentos deben definir en sus grandes lineamientos las atribuciones legales del sector público o, dicho de otra manera, deben establecer las reglas del juego que han de determinar la conducta del sector público y la regulación del mercado. No puede subestimarse la importancia de estas reglamentaciones. Varios autores, entre ellos Buchanan, Alesina, von Hagen, Poterba, Tabellini y Persson, sostienen que las disposiciones políticas como el federalismo o la descentralización fiscales, la representación parlamentaria proporcional o no proporcional, la frecuencia de las elecciones, el gobierno presidencial frente a otros tipos de gobierno, el papel del ministerio de hacienda como una especie de superminis- terio, los reglamentos que rigen el proceso presupuestario - por ejemplo, si comienza con restricciones macroeconómicas que reflejan la valoración colectiva de prioridades o si permite que las presiones sobre el gasto deriven de la influencia política de cada ministro-, si el parlamento puede o no modificar el contenido de las

\footnotetext{
${ }^{17}$ Centros de este tipo existen actualmente en Boloña (Italia) y en Salvador de Bahía (Brasil). En Boloña se proyecta permitir el acceso a este centro de trámite único a través del internet.

${ }^{18}$ En algunos países podría decirse que se heredan los altos puestos de la administración pública. Algunos empleos en determinadas instituciones pasan de uno a otro miembro de una misma familia. En otros países la afiliación partidista abre las puertas a los puestos de gobierno y el cambio de gobierno crea gran número de vacantes, porque muchos empleos se consideran prebendas políticas.
} 
propuestas presupuestarias, o si debe votar sobre el presupuesto en su conjunto, si el banco central es independiente o no, y así sucesivamente, tienen todas un impacto importante sobre los resultados fiscales y macroeconómicos. ${ }^{19}$ Se han construido modelos a base de estas situaciones aplicando fuertes hipótesis y sofisticadas teorías del juego que luego han sido sometidas a pruebas empíricas (véase, entre otros, Tabellini y Persson, por publicarse, y Poterba y von Hagen, eds., 1999).

No pasaré revista a esta literatura, todavía en plena evolución, y que a veces ha llegado a conclusiones conflictivas. Sin desconocer su importancia y su valor potencial en la explicación de la política económica, en este artículo se abordarán otros aspectos, específicamente los relativos a la calidad de las instituciones públicas. Los reglamentos políticos y de procedimiento seguramente tendrán más influencia sobre las polí- ticas que la calidad del sector público o de las instituciones públicas. Son estas instituciones las que hacen frente a la ciudadanía y que ponen en práctica las políticas. Evidentemente, al cambiar los incentivos que mueven a los políticos y a las instituciones a actuar, los reglamentos políticos y de procedimiento pueden influir sobre la conducta y la calidad de las instituciones, y viceversa. Los reglamentos no son más que una serie de instrucciones. No son en sí políticas. Hasta no entrar en el juego, no son más que pedazos de papel; y el juego está en manos de las instituciones encargadas de cumplir esas instrucciones. ${ }^{20}$ Pueden o no acatar las instrucciones en forma leal y eficiente. ${ }^{21} \mathrm{El} \mathrm{sec-}$ tor público está compuesto de muchas instituciones, algunas de las cuales tienen mayor importancia que las otras. La conducción y eficiencia de estas instituciones determinan en alto grado la calidad del sector público.

\section{IV}

\section{La calidad de las instituciones públicas}

En la calidad del sector público puede influir la falta de algunas instituciones esenciales o el deficiente desempeño de las existentes. Por ejemplo, en muchos países no hay instituciones encargadas de velar por la competencia o que obliguen a las instituciones financieras a declarar sus operaciones en forma completa o a las empresas a publicar cuentas satisfactorias cuando sus acciones se transan en el mercado de valores. En consecuencia, el mercado puede funcionar deficientemente por las influencias del compadrazgo o los poderes del monopolio o por falta de informaciones esenciales. El desempeño de las instituciones públicas depende de muchos factores, entre otros i) la tradición y la buena reputación; ii) los recursos con que cuentan y la discreción que tienen para usarlos; iii) la clara definición de su mandato; iv) sus organizaciones; v) los incentivos que se les ofrecen; vi) la calidad de su liderazgo y de su personal, y vii) la libertad de acción que tienen en cuanto a reorganización.

\footnotetext{
19 Ricardo Haussmann apoya la existencia de un consejo fiscal independiente que restrinja la acumulación anual de la deuda pública dentro de un nivel acordado. Es evidente el parecido con el concepto de un banco central independiente. Otros sostienen que la política fiscal debe hasta cierto punto aislarse de las presiones políticas (véase, por ejemplo, Blinder, 1997, y Kopits y Symansky, 1998).
}

Tomemos como ejemplo una de las instituciones más fundamentales, a saber, la administración tributaria. Su eficiencia dependerá en parte de su tradición y reputación. Una administración tributaria que ha demostrado ser eficiente, honrada y orgullosa de su labor en el pasado probablemente continuará por la misma senda en el futuro, a menos que sufra conmociones verdaderamente fundamentales. Del mismo modo, es muy difícil a corto plazo cambiar a una administración corrupta e ineficiente. ${ }^{22}$ Su eficiencia dependerá también de los recursos que se le asignen para contratar a personal capacitado y pagarle buenos sueldos, invertir en la tecnología computacional, realizar las auditorías necesarias, etc. La claridad de su mandato - por ejemplo, para hacer cumplir las leyes tributarias en forma justa y objetiva- es importante. También es esencial su independencia de las presiones políticas en su labor cotidiana. Surgen los problemas cuando su

\footnotetext{
${ }^{20}$ Podría sostenerse que hay dos series de juegos en desarrollo. El primero establece las reglas y el segundo las aplica.

${ }^{21}$ En un estudio reciente señalé que la política pública a menudo se ve distorsionada por la existencia de problemas vinculados a la relación principal-agentes (véase Tanzi, por publicarse).

22 En algunos países se ha optado por cerrar oficinas administrativas y abrir otras nuevas, con lo cual se empieza de cero.
} 
mandato se vuelve confuso, ya sea porque la legislación no es transparente o porque la institución está sometida a una interferencia política que la obliga a acomodarse a las circunstancias especiales de algunos contribuyentes, como ha ocurrido en algunas economías en transición y en países en desarrollo. ${ }^{23}$ En esos países, la interferencia política ha menoscabado la calidad de la administración tributaria. La organización de la administración tributaria también reviste importancia, así como la serie de incentivos que se le ofrecen. Si una institución está mal organizada, o si se compensa por igual el buen y el mal desempeño, será escasa la contribución de esta institución a la calidad del sector público. ${ }^{24}$

Actualmente hay iniciativas en marcha encaminadas a fortalecer los incentivos para la administración tributaria dándole la misma independencia que tienen los bancos centrales, ${ }^{25}$ y negociando contratos explícitos entre el gobierno y la administración tributaria en que se especifican rendimientos cuantitativos. En Australia, por ejemplo, el gobierno garantiza a la administración tributaria un determinado volumen de recursos para un trienio, y ésta, por su parte, se compromete a entregar algunos resultados y productos cuantificados. ${ }^{26}$

Aquí conviene destacar otros dos aspectos relacionados de las instituciones públicas, a saber i) la sinergia entre las instituciones públicas y ii) los mecanismos de coacción. Estos se tratan aquí como dos aspectos separados, aunque son, en gran medida, las dos caras de una misma moneda.

\section{La sinergia}

Como las distintas partes de un mismo sistema ecológico, las instituciones públicas operan juntas y se apoyan unas a otras de manera que es muy posible que no pueda existir, digamos, una administración tributaria de primera clase en un medio en que las demás instituciones, como la tesorería o importantes ministerios, o el poder judicial o incluso el correo, no funcionan

\footnotetext{
23 Véase, por ejemplo, Tanzi, 1998a.

24 Los reglamentos sobre la contratación, ascenso y despido de funcionarios públicos y asuntos similares tienen evidentemente mucha importancia en la determinación de la calidad del sector público.

${ }^{25}$ En cambio, la administración tributaria tiene mayor discreción en el uso de recursos.

${ }^{26} \mathrm{El}$ costo de recaudación puede tener alguna influencia a este respecto (véase Highfield, 1999).
}

bien. ${ }^{27}$ Frecuentemente las mismas deficiencias afectan a varias instituciones, lo que implica que los intentos por mejorar sólo a una, cuando las demás necesitan la misma atención, no dará los resultados apetecidos a largo plazo. Así ha ocurrido en las economías en transición en que, por ejemplo, el establecimiento de un buen sistema de tesorería no se ha traducido en un gran mejoramiento de la calidad de la gestión del gasto público ya que el proceso de preparación presupuestaria ha seguido generando presupuestos tan irreales que la tesorería no ha podido ni financiar ni administrarlos. En algunos casos se ha producido así una acumulación de atrasos de pagos fiscales y, como contraparte, la acumulación de obligaciones impagas por parte de los contribuyentes (véase Potter y Diamond, 1999).

Las externalidades interinstitucionales (negativas y positivas) tienen mucha importancia y deben reconocerse y tratarse en todo intento por mejorar la calidad del sector público. Por desgracia, que yo sepa, este aspecto no ha sido planteado por los estudiosos. Por ejemplo, cuando el poder judicial no funciona bien, muchas otras instituciones se ven afectadas. Lo mismo vale para el sistema educativo. Probablemente es necesario aplicar un criterio holístico en que se aborden a un mismo tiempo los problemas de distintas instituciones. Sin embargo, este criterio - siempre difícil de aplicar- debe estar orientado por una clara estrategia y por un concatenamiento adecuado de las enmiendas requeridas y realizadas. Si este método demora más tiempo que el mandato político del gobierno que lo aplica, es menos probable que el proceso se cumpla cabalmente. Por ello, la calidad del sector público se modifica sólo lentamente con el tiempo.

\section{Mecanismos de coacción}

La calidad del sector público dependerá en alto grado de la existencia de controles y mecanismos de coacción. Algunos de estos mecanismos deben operar dentro de las propias instituciones. Por ejemplo, una auditoría interna eficiente se refleja en un mejor funcionamiento de las instituciones y da alguna garantía de que éstas no se apartarán de su mandato fundamental. Pero estos mecanismos pueden no ser suficientes. En otras

\footnotetext{
27 Por ejemplo, en los países en que la evasión tributaria no es castigada por la ley, será más difícil que la administración tributaria combata este fenómeno. En países en que no funciona bien el correo, la administración no podrá confiar en él para comunicarse con el contribuyente, y viceversa.
} 
ocasiones los mecanismos de coacción deben abarcar varias instituciones, como es el caso de las instituciones superiores de auditoría que se especializan en el control y la ejecución y tienen la responsabilidad de controlar el gasto y la recaudación de ingresos fiscales. Estas instituciones frecuentemente reciben su mandato de la constitución y actúan como entes independientes.

Ejemplos de estas instituciones superiores de auditoría son el General Accounting Office en los Estados Unidos, la Court des Comptes de Francia y la Corte dei Conti de Italia, así como la Contraloría General que tienen muchos países latinoamericanos. Históricamente, estas entidades de auditoría se han preocupado de velar por que las instituciones cumplan más bien con la letra que con la intención de la ley. Así, muchas veces se ha prestado menor atención a los productos y resultados de las instituciones que a su cumplimiento de requisitos legales. Este tipo de auditoría tiene escasa utilidad, salvo quizá para asegurar el cumplimiento de las disposiciones, porque no promueve la calidad del sector público en su objetivo fundamental de servir al público. No garantiza que el público reciba los servicios que merece por el dinero que gasta el sector público.

En años recientes se ha iniciado una campaña para prestar más atención a la eficiencia y la producción que a las formalidades y los insumos. Se trata de evaluar el gasto público en función de su economía, eficiencia y eficacia. Para esa evaluación se requieren indicadores de la eficiencia de la gestión y del costo de las actividades del sector público. Los exponentes principales de este movimiento están en Australia y Nueva Zelandia, pero, en distintas formas, el movimiento avanza en otros países. ${ }^{28}$ Esta nueva tendencia se ha traducido en muchos cambios en las disposiciones contractuales y la organización de las instituciones públicas. Por ejemplo, en los países que han adoptado este criterio ha desaparecido la inamovilidad en los cargos de

\footnotetext{
${ }^{28}$ Aunque el sistema australiano al comienzo centraba su atención en los resultados del gasto fiscal, el sistema de Nueva Zelandia siempre se ha concentrado en el producto cuantificable. Debe aclararse que los productos y los resultados no son la misma cosa. Los resultados pueden ser más difíciles de medir y pueden verse afectados por el gasto público con grandes rezagos. Por ejemplo, el gasto en educación puede valorarse en función del número de estudiantes (un producto) o en función del crecimiento del capital humano (un resultado). La salud puede evaluarse en función del número de operaciones realizadas o en función de su impacto sobre la duración y calidad de vida. Evidentemente, la meta del gobierno debe ser influir sobre los resultados pero éstos son más difíciles de medir que los productos.
}

la administración pública y se han eliminado muchas restricciones que antes entrababan la acción de los jefes de departamento. El gobierno, como ejecutor principal, contrata ahora con un organismo público lo que éste debe entregar y el jefe del organismo es personalmente responsable del resultado. Si las metas acordadas no se cumplen, no se renuevan los contratos de los jefes de los organismos o se reducen sus sueldos. Se establecen así fuertes incentivos económicos para la eficiencia. Queda por evaluar cuál sería el impacto final de esta reforma en culturas distintas de las de Australia y Nueva Zelandia. ${ }^{29}$ Sería difícil, por ejemplo, aplicar esta reforma en países en que cuesta despedir a los empleados cualquiera sea su desempeño. Fácilmente se advierte el conflicto entre este criterio y el espíritu que anima la constitución italiana.

No estaría completo el análisis de los mecanismos de coacción y los controles sin detenerse en dos puntos fundamentales. ${ }^{30} \mathrm{El}$ primero se refiere a las deficiencias de la contabilidad financiera, que tradicionalmente ha caracterizado la medición de las operaciones del gobierno, como instrumento para lograr buenos controles de la eficiencia. El segundo se relaciona con la medición de las reacciones y preferencias de los consumidores con respecto a los servicios que prestan los entes públicos, tema que recién comienza a estudiarse. Antes de entrar en estos dos aspectos, cabe señalar que todo concepto de la calidad de los servicios gubernamentales debe relacionarse con el costo de esos servicios y los recursos disponibles para generarlos. Cuanto mayores sean los recursos disponibles, tanto mejor cabría esperar que fueran los servicios públicos. Sin embargo, con un nivel dado de recursos disponibles, cuanto más eficiente sea el organismo público, mejor será la calidad de sus servicios.

El primer problema entonces es la medición del nivel de recursos empleado. Tradicionalmente las cuentas fiscales (y por lo tanto el presupuesto) se han apoyado en la contabilidad financiera o en las transacciones financieras. Así por ejemplo, el costo del organismo X se mide por la transferencia financiera que ese organismo recibe del presupuesto. Sin embargo, las cuentas basadas en las transacciones financieras adolecen de muchas deficiencias que ahora reconocen en mayor grado los contadores y economistas. Está ahora bien establecida la necesidad de la contabilidad por

\footnotetext{
${ }^{29}$ Schick (1998) hace una evaluación escéptica de esta reforma. ${ }^{30}$ Agradezco a Barry Potter por haberme señalado estos dos puntos.
} 
base devengada, en principio, aunque las dificultades prácticas de su utilización probablemente posterguen por algún tiempo el abandono de la contabilidad financiera. ${ }^{31}$ La contabilidad de base devengada mide con mayor precisión los verdaderos costos de las actividades del sector público; por lo tanto, con ella sería posible una auditoría mucho más significativa para la comparación de los resultados con los costos verdaderos. Por ejemplo la contabilidad financiera pasa por alto el costo de oportunidad de utilizar los activos del sector público cuando este uso no se refleja en una transferencia financiera (véase Tanzi y Prakash, por publicarse). Por lo tanto, una actividad que recibe pocas transferencias financieras pero que usa terrenos o edificios muy valiosos se mide ahora como que tuviera costos bajos, lo que evidentemente es un error.

El segundo problema se refiere al papel de la ciudadanía, como contribuyentes y consumidores de los servicios públicos, cuando evalúan estos servicios. La mayoría de las reformas hasta la fecha, sobre todo las reformas de las instituciones en que se distingue entre el mandante principal (el gobierno) y el agente (el organismo público), representan contratos reales o implícitos entre dos intereses de producción. Un ejemplo del sector privado podría ser el contrato entre un regulador en el sector privado y la industria monopolista que regula. El ente regulador se supone que en cierto sentido representa al consumidor: pero su papel directo es fundamentalmente el de evitar utilidades excesivas para el productor más bien que velar concretamente por los intereses del consumidor. Lo que falta en las disposiciones administrativas de Australia y Nueva Zelandia es la voz del consumidor. A diferencia del sector privado en que el consumidor puede expresar sus preferencias en forma directa (siempre que haya un grado adecuado de competencia en el mercado), esta posibilidad no existe en los servicios públicos. Por lo tanto, algunas reformas en el decenio de 1990 se orientaron a la búsqueda de indicadores sucedáneos de las preferencias del consumidor. Conviene mencionar por lo menos tres métodos:

i) Algunas evaluaciones han pulsado la opinión de determinados consumidores, no en relación con una encuesta de consumo organizada, sino como parte de un ejercicio más amplio destinado a conocer, por ejemplo, la opinión de los padres sobre la educación que

\footnotetext{
${ }^{31}$ El Departamento de Estadísticas del FMI está preparando un nuevo manual de estadísticas financieras gubernamentales basado en la contabilidad de base devengada.
}

se da a sus hijos. Estas iniciativas han tendido a ser de índole parcial y limitadas a sectores individuales.

ii) Otras investigaciones se han basado en encuestas formales de consumo que pueden abarcar diferentes servicios. El Banco Mundial y algunos países o instituciones han tomado iniciativas de este tipo. ${ }^{32}$ Aunque estas iniciativas representen cierto avance, las limitaciones del método son también importantes. Por un lado se basa esencialmente en las opiniones, en vez de medir algunas acciones o proporcionar una respuesta específica de parte del consumidor sobre sus preocupaciones cualitativas; por otro, se plantea el problema, corriente en las encuestas bien preparadas, de que rinda opiniones más positivas de las que podrían justificarse por los servicios que presta el sector público.

iii) Estas deficiencias tanto de las evaluaciones como de las encuestas de consumo llevaron al Reino Unido a comienzos del decenio de 1990 a buscar otro método. De esta iniciativa surgió la "Carta del consumidor" que trata de involucrar al ciudadano en el establecimiento de estándares. Se han aplicado varios sistemas para lograrlo. Los representantes de la ciudadanía u otros intereses que agrupan a los consumidores participan en el establecimiento de estándares y contratos de resultados entre el gobierno y los organismos, más bien que solamente el ministerio de hacienda. Además, una vez que se han establecido los estándares, se da a los consumidores el derecho y los medios para quejarse, estableciendo líneas telefónicas de atención permanente, etc. La respuesta del consumidor se toma en cuenta cuando se evalúa el resultado general de la gestión del director del organismo. La obligación de que los funcionarios usen tarjetas de identificación, de manera que los consumidores, con su respuesta, puedan tanto premiar a los buenos como castigar a los malos, es un elemento pequeño pero significativo. Este es otro ejemplo de cómo se están introduciendo lentamente los incentivos en el sector público. Además, en algunos casos, los consumidores tienen derecho a algún tipo de compensación si es que el que provee el servicio público no cumple con los estándares requeridos. El ejemplo más sencillo es el reembolso a que tienen derecho los abonados a boletos estacionales en ciertas líneas férreas cuando la demora de los trenes excede cierto límite.

\footnotetext{
${ }^{32}$ Por ejemplo, se ha pedido a los usuarios de los hospitales públicos que evalúen la calidad de los servicios, o a los contribuyentes se les pide su opinión sobre algunos aspectos de la administración tributaria.
} 
Ninguno de estos métodos es del todo satisfactorio, pero la injerencia del consumidor en el establecimiento de normas, su juicio sobre el cumplimiento o incumplimiento de esas normas y, por ende, su influencia en la asignación futura de los recursos del sector público, probablemente será una preocupación importante en los próximos años. También es probable que los incentivos y las penalidades desempeñen un papel cada vez más importante en la promoción de una mejor calidad de servicio en el sector público.

Además de los controles internos y los que aplican las instituciones de auditoría como el GAO o la Court des Comptes, hay varias otras instituciones cuya labor y eficiencia son un ingrediente esencial para mejorar la calidad de todo el sector público. Entre ellas tiene suma importancia el sistema judicial. Es fundamental el papel que desempeña en todas sus manifestaciones: cumplimiento de contratos, protección de los derechos de propiedad, protección de la seguridad personal, control de la corrupción y mejoramiento de la eficiencia de otras instituciones. No es ninguna exageración asegurar que la calidad del sector público de un país y el funcionamiento de su mercado dependen en alto grado de la actuación del sistema judicial. Por esta razón está mereciendo mucha atención en varios países europeos, como Francia, Italia y Portugal, y en la mayoría de los países latinoamericanos.

En muchos países el sistema judicial ha entrado en crisis en años recientes. No se protegen los derechos de los individuos ni los de la propiedad, no se cumplen los contratos, los procesos judiciales duran años o hasta decenios y así sucesivamente. En muchos casos los individuos que quebrantan la ley no reciben castigo alguno, o sólo un castigo muy leve o son castigados tan tarde que el efecto disuasivo de la pena se disipa. En algunos países el lento o hasta corrupto sistema de justicia proporciona un incentivo implícito para la evasión tributaria, para la corrupción y para otras actividades ilícitas, porque los que son sorprendidos cometiendo estos delitos pueden contar con la ineficiencia o la venalidad del sistema judicial para eludir la pena. En algunos países el gobierno se demora diez años en determinar si alguien acusado de evasión tributaria debe o no pagar los impuestos debidos. Además a menudo las penalidades aplicadas son insignificantes. Esto ofrece un buen ejemplo de las externalidades a través de instituciones que se mencionaron anteriormente. Lo mismo puede ocurrir con quienes no cumplen los términos de un contrato. Por ejemplo, la proliferación de deudas impagas y crisis financieras es en parte consecuencia directa de que se aplican penalidades demasiado bajas y con mucha demora con quienes no cumplen sus obligaciones financieras. ${ }^{33} \mathrm{En}$ algunos países los dueños prefieren dejar vacíos sus departamentos o casas antes que arrendarlos, por la dificultad que tendrán después para recuperarlos al término del contrato. Evidentemente la falencia del sistema judicial estimula a los arrendatarios a pasar por alto los términos de sus contratos e impone costos de eficiencia a la sociedad.

Cuando la justicia es corrupta o ineficiente también es injusta, porque algunas personas son más hábiles que otras para aprovechar sus puntos flacos. Los ciudadanos respetuosos de la ley son los que terminan por pagar los precios más altos, y la actividad económica se resiente. El igual acceso a la justicia, y a una justicia que se administra en forma oportuna, debe ser una de las metas fundamentales del Estado. Es también uno de los principales requisitos de un mercado eficiente. Si no se cumple esta meta, el sector público seguirá siendo de baja calidad (véase Guigou, 1999).

\section{V}

\section{Medición de la calidad general del sector público}

Aunque personas conocedoras de cada país tienen algunas nociones a priori sobre la calidad general del sector público, sería difícil o hasta imposible establecer mediciones objetivas de ella. En principio se pueden efectuar estudios sobre las apreciaciones de esa calidad usando las mismas técnicas que se emplean, por ejemplo, en los estudios de la corrupción. Sin embar- go, para obtener resultados aceptables de estas encuestas serían muy grandes las exigencias en materia de

\footnotetext{
${ }^{33}$ En muchos países la bancarrota se ha convertido en un asunto trivial de escasa trascendencia. Por ello se ha convertido en un problema importante en muchos países el establecimiento de una legislación sobre esta materia.
} 
información por parte de los respondientes y la calidad de las respuestas no sería muy alta. Podría ser más fácil evaluar la calidad de cada una de las principales instituciones que componen el sector público y ponderar de alguna manera su importancia para la calidad de ese sector en conjunto. Sin embargo, por el número de esas instituciones y los conocimientos requeridos para evaluarlas, también esa iniciativa resultaría muy costosa y no necesariamente eficiente para obtener los resultados deseados. Otro método sería simplemente el de medir los resultados económicos y sociales de la gestión pública de un país: se centraría la atención en los productos o mejor aún en los resultados y se atribuirían éstos a la calidad del sector público. Sin embargo este método también tendría sus limitaciones.

En años recientes, algunas instituciones y algunos estudiosos han empezado a analizar características particulares que representan aspectos importantes de la calidad de los sectores públicos. El FMI, por ejemplo, se ha ocupado de las estadísticas que los países pueden producir y dar a conocer al público. Algunas de ellas se relacionan con el sector público. La hipótesis es que los países que pueden generar buenas estadísticas sobre el sector público y están dispuestos a publicarlas oportunamente tienen un sector público de mejor calidad. ${ }^{34}$ El Fondo ha comenzado también a evaluar la transparencia de la política y de las instituciones fiscales. Esta evaluación se basa en una serie de principios generales de transparencia fiscal. Se supone que la falta de transparencia es una indicación de una calidad inferior del sector público, y que ella promueve la ineficiencia, las políticas erradas y diversos problemas de ejercicio del poder. En el futuro podrían prepararse informes de transparencia para la mayoría de los países. Si fueran comparables y completos, estos informes podrían servir de indicadores vicarios para la evaluación oficiosa de la calidad del sector público.

En años recientes se ha prestado mucha atención a los problemas del ejercicio del poder y la corrupción en las instituciones públicas. Estos problemas también inciden en la calidad del sector público. Se ha reconocido que la falta de transparencia en la forma en que funcionan las instituciones, así como la falta de controles, promueven la ineficiencia y la corrupción. Existe ahora una amplia literatura sobre la transparencia y la corrupción. Australia y Nueva Zelandia nuevamen-

\footnotetext{
${ }^{34}$ Las estadísticas mismas quizá serían más indicativas de la calidad de la política pública que de la calidad del sector público.
}

te han sido pioneros en la promoción de técnicas para aumentar la transparencia. En la nueva "arquitectura" del sistema financiero internacional se ha recomendado que los países aumenten la transparencia en su proceso de preparación de políticas. Una mayor transparencia probablemente equivaldría a una menor corrupción y en general a una más alta calidad y eficiencia del sector público. Sin embargo queda mucho por investigar sobre estas relaciones. Cabe también reconocer que las pruebas de transparencia pueden ser tanto superficiales como profundas. Las superficiales no serían muy útiles para comprender lo que está sucediendo en el sector público, y las profundas pueden exigir muchos recursos altamente especializados y onerosos.

La corrupción es un síntoma de la baja calidad del sector público. Diversos grupos han preparado índices de corrupción para gran número de países (véase Tanzi, 1998b). Se supone que estos índices miden las "percepciones" de la corrupción. Es probable que en cierto grado y suponiendo que esas percepciones reflejan la realidad, estos índices de corrupción puedan también ser indicadores vicarios de la calidad del sector público. Sin embargo, hay que proceder con cautela porque aparte el problema de la calidad de los índices de corrupción, un país podría tener una burocracia o incluso un liderazgo político de intachable honestidad con políticas e instituciones muy ineficientes. Aunque sea importante, la corrupción es sólo un aspecto de la mala calidad del sector público.

Algunos autores, como Rauch y Evans (por publicarse) han presentado estimaciones de la eficiencia burocrática para muchos países en desarrollo, con lo cual dan mediciones de otra variable que se relaciona con la calidad del sector público. Por su parte, Keefer y Knack (1997), después de definir la calidad institucional como la evaluación objetiva de las instituciones que protegen la propiedad y los derechos contractuales, intentan una medición basada en varios indicadores. No se sabe a ciencia cierta hasta qué punto estos indicadores miden la calidad de las instituciones del sector público.

Hay otras variables que pueden dar informaciones sobre la calidad del sector público. Algunas se relacionan con su eficiencia, otras con las políticas adoptadas. Por ejemplo, la relación entre el gasto en una categoría determinada -digamos salud y educación- y el resultado de ese gasto - como vidas salvadas, operaciones exitosas, reducción en la incidencia de ciertas enfermedades, logros educativos- serían una indicación de eficiencia (véase Gupta, Honjo y Verhoeven, 
1997). En cambio las mediciones sobre la capacidad de sustentación fiscal podrían más bien estar indican-

\section{VI}

\section{Conclusiones}

La calidad del sector público sólo puede apreciarse con el trasfondo del papel que desempeña el Estado. Si el sector público permite que el Estado cumpla sus metas en una forma eficiente y bien lograda, puede decirse que el sector público es de alta calidad. Sin embargo, las metas deben ser realistas, porque, por muy eficiente que sea el sector público, no podrá cumplir metas que no sean alcanzables. Así pues, en general, la calidad del sector público no puede medirse según la calidad de los resultados de la política aunque los dos están estrechamente unidos, sobre todo a largo plazo.

En general, un sector público eficiente debe ser capaz de lograr los objetivos del Estado con un grado mínimo de distorsión del mercado, con la carga más baja posible de tributación para los imponentes, con el menor número de empleados públicos y con la menor absorción de recursos económicos por el sector público. El sector público debe ser transparente en sus procesos y en sus resultados. La corrupción no debe desempeñar papel alguno en las decisiones que tomen los burócratas y los dirigentes políticos. Y los recursos que están en manos del sector público deben usarse en aplicaciones que maximicen su tasa social de rendimiento. Un sector público de esa índole sería claramente uno que "hace crecer el mercado" para usar una expresión que está de moda. Un sector público de esa especie prestaría especial atención a la protección de los derechos de propiedad y al cumplimiento de los contratos. do una política deficiente y no la mala calidad del sector público.
La calidad del sector público es también importante en la consecución del objetivo de equidad, considerado ahora como uno de los objetivos fundamentales del Estado. Un sector público que en todas sus dimensiones facilita el logro de la equidad debe, ceteris paribus, ser considerado de calidad superior al que no lo hace. Sin embargo, como dijimos anteriormente, es difícil definir el papel óptimo del Estado en esta área y es fácil identificar los desincentivos que podrían crear algunas políticas encaminadas a redistribuir el ingreso. Es más probable que se produzcan estos efectos cuando el sector público es de baja calidad, de manera que las políticas pueden más fácilmente distorsionarse en la etapa de ejecución (véase, por ejemplo, Alesina, Danninger y Rostagno, 1999, y Schansberg, 1996). Un sector público de alta calidad debiera permitir la consecución de la equidad a un menor costo en términos de eficiencia. ${ }^{35}$

Por último, el análisis presentado en este documento destaca que las llamadas "reformas de primera generación", tan populares en muchos países en los decenios de 1980 y 1990, no mejoran necesariamente la calidad del sector público, aunque puedan mejorar la calidad de la política pública. En realidad, la aspiración a lograr las "reformas de primera generación" ha puesto de manifiesto la necesidad de mejorar la calidad del sector público. Para que ello suceda son necesarias las "reformas de segunda generación".

(Traducido del inglés)

\section{Bibliografía}

Alesina, A., S. Danninger y M. Rostagno (1999): Redistribution Through Public Employment: The Case of Italy, IMF working paper, $\mathrm{N}^{\circ} 177$, Washington, D.C., Fondo Monetario Internacional (FMI), diciembre.

Banco Mundial (1997): The State in a changing world, World Development Report, Washington, D.C.

Blinder, A. (1997): Is government too political?, Foreign Affairs, vol. 76, $\mathrm{N}^{\circ} 6$, Nueva York, Council on Foreign Relations, Inc.

Braibant, G. (1996): Utilité et difficultés de la codification, Droits, $\mathrm{N}^{\circ} 24$, París, Presses Universitaires de France, diciembre.
Charap, J. y C. Harm (por publicarse): Institutionalized corruption and the kleptocratic State, C. Menard (ed.), Institutions, Contracts and Organizations: Perspectives from New Institutional Economics, Northampton, Massachusetts, Edward Elgar.

${ }^{35}$ Sen (1999) asigna un importante papel en esta materia al Estado. Identifica el desarrollo con la libertad y asigna al Estado la función de dar acceso a la educación y a la salud para todos. Un sector público de alta calidad facilitaría el logro del objetivo de Sen. 
Davis, K. y M. J. Trebilcock (1999): What role do legal institutions play in development?, trabajo presentado a la Conference on Second Generation Reforms, Washington, D.C., FMI, 8 y 9 de noviembre.

De Soto, H. (1987): El otro sendero, Buenos Aires, Editorial Sudamericana, tercera edición.

Dethier, J. J. y T. Shapiro (1998): Constitutional rights and the reform of social entitlements, L. Bokros y J. J. Dethier (eds.), Public Finance Reform During the Transition: The Experience of Hungary, Washington, D.C., Banco Mundial.

Dixit, A. K. (1996): The Making of Economic Policy, Cambridge, Massachusetts, MIT Press.

Ferro, P., S. Lo Faso y G. Salvemini (1999): L'azione della pubblica amministrazione per la competitività internazionale in presenza di vincoli di finanza pubblica, M. Bordignon y D. Da Empoli (eds.), Concorrenza fiscale in un'economia internazionale integrata, Roma, Franco Angeli.

FIEL (Fundación de Investigaciones Económicas Latinoamericanas) (1988): Los costos del Estado regulador, Buenos Aires.

Fiorentini, G y S. Zamagni, eds. (1999): The Economics of Corruption and Illegal Markets, Northampton, Massachusetts, Edward Elgar.

Forte, F., ed. (1998): Le regole della costituzione fiscale, Politeia, año $14, \mathrm{~N}^{\circ} 49$, Milán, Italia, Politeia.

Guigou, E. (1999): Justice: Du Ministère des Affaires au Ministère du Droit, Le Monde, París, 1 de septiembre.

Gupta, S., K. Honjo y M. Verhoeven (1997): The Efficiency of Government Expenditure: Experiences in Africa, IMF working paper, $\mathrm{N}^{\circ} 153$, Washington, D.C., FMI.

Guy, S. (1996): Une utopie: la codification, Revue française de droit constitutionnel, $\mathrm{N}^{\circ} 26$, París, Presses Universitaires de France.

Highfield, R. (1999): Tax administration: Understanding and using the cost of collection ratio, Washington, D.C., noviembre, mimeo.

Jacobs, S. H. (1999): The second generation of regulatory reforms, trabajo presentado a la Conference on Second Generation Reforms, Washington, D.C., FMI, 8 y 9 de noviembre.

Keefer, P. y S. Knack (1997): Why don't poor countries catch up? A cross-national test of an institutional explanation, Economic Inquiry, vol. XXXV, Huntington Beach, California, Western Economic Association, julio.

Kopits, G y S. Symansky (1998): Fiscal Policy Rules, Occasional paper, $\mathrm{N}^{\circ} 162$, Washington, D.C., FMI.

Laffont, J. J. y J. Tirole (1993): A Theory of Incentives in Procurement and Regulation, Cambridge, Massachusetts, MIT Press.

Landes, D. S. (1999): The Wealth and Poverty of Nations: Why Some are So Rich and Some So Poor, Nueva York, W.W. Norton \& Company.

La Porta, R., F. Lopez-de-Silanes, A. Shleifer y R. Vishny (1998): The quality of government, Cambridge, Massachusetts, agosto.

Martino, A. (1989): Fisco e costituzione, V. Uckmar (ed.), Esperienze straniere e prospettive per l'ordinamento tributario italiano, Padua, Italia, Italia, CEDAM.

Mattarella, B. G. (1994): La codification du droit: réflexions sur l'expérience française contemporaine, Revue française de droit administrative, vol. 10, $\mathrm{N}^{\circ} 4$, París, Sirey, julio-agosto.

Musgrave, R. A. (1959): The Theory of Public Finance, Nueva York, McGraw-Hill.

North, D. C. y R. Thomas (1973): The Rise of the Western World: A New Economic History, Cambridge, Reino Unido, Cambridge University Press.

North, D. C. y B. Weingast (1994): Constitutions and commitment: The evaluation of institutions governing public choice in seventeenth century England, T. Persson y G. Tabellini (eds.),
Monetary and Fiscal Policy, vol. 1, Cambridge, Massachusetts, MIT Press.

Nozick, R. (1974): Anarchy, State and Utopia, Nueva York, Basic Books.

OCDE (Organización de Cooperación y Desarrollo Económicos) (1999): OECD Economic Outlook, París, diciembre.

Poterba, J.M. y J. Von Hagen (eds.) (1999): Fiscal Institutions and Fiscal Performance, Chicago, Illinois, National Bureau of Economic Research, Inc. (NBER)/University of Chicago Press.

Potter, B. y J. Diamond (1999): Guidelines for Public Expenditure Management, Washington, D.C., FMI.

Rauch, J. E. y P. B. Evans (por publicarse): Bureaucratic structure and bureaucratic performance in less developed countries, Journal of Public Economics, Amsterdam, Países Bajos, Elsevier Science B.V.

Reviglio, F. (1999): Budget transparency for public expenditure control: The case of Italy, Washington, D.C., diciembre, mimeo.

Rodotá, S. (1995): Le libertà e i diritti, R. Romanelli (ed.), Storia dello Stato italiano, Roma, Donzelli Editore.

Schansberg, D. E. (1996): How Poor Government Policy Harms the Poor, Boulder, Colorado, Westview Press.

Sen, A. (1999): Development as Freedom, Nueva York, Alfred A. Knoph.

Schick, A. (1998): Why most developing countries should not try New Zealand's reforms, The World Bank Research Observer, vol. 13, $\mathrm{N}^{\circ} 1$, Washington, D.C., Banco Mundial, febrero.

Skaperdas, S. y C. Syropoulos (1995): Gangs as primitive states, G. Fiorentini y S. Peltzman (eds.), The Economics of Organised Crime, Cambridge, Reino Unido, Cambridge University Press.

Smith, D. y E. Richardson (1999): The readability of Australia's taxation laws and supplementary material: An empirical investigation, Fiscal Studies, vol. 20, $\mathrm{N}^{\circ} 3$, Londres, Institute for Fiscal Studies, septiembre.

Tabellini, G. y T. Persson (por publicarse): Fiscal Policy in Representative Democracies, Cambridge, Massachusetts, MIT Press.

Tan, L. M. y G. Tower (1992): Readability of tax laws: An empirical study in New Zealand, Australian Tax Forum, vol. 9, $\mathrm{N}^{\circ} 3$, Clayton, Victoria, Australia, Monosh University.

Tanzi, V. (1995): Corruption: arm's-length relationships and markets, G. Fiorentini y S. Peltzman (eds.), The Economics of Organised Crime, Cambridge, Reino Unido, Cambridge University Press.

(1998a): Essential Fiscal Institutions in Selected Economies in Transition, Discussion paper, $\mathrm{N}^{\circ} 53$, Washington, D.C., Collegium Budapest, Institute for Advanced Study, noviembre.

(1998b): Corruption Around the World, Staff papers, vol. 45, $\mathrm{N}^{\circ}$ 4, Washington, D.C., FMI, diciembre.

(por publicarse): Rationalizing the government budget: Or why fiscal policy is so difficult, A. O. Krueger, Economic Policy Reform: The Second Stage, Chicago, Illinois, University of Chicago Press.

Tanzi, V. y T. Prakash (por publicarse): The cost of government and the use of public assets, Washington, D.C.

Tanzi, V. y H. Zee (1997): Fiscal Policy and Long-Run Growth, Staff papers, vol. 44, $\mathrm{N}^{\circ}$ 2, Washington, D.C., FMI, junio.

United States Congress, Senate Committee on the Budget (1984): President's private sector survey on cost control (Grace Commission): Hearing before the Committee on the Budget, United States Senate, Ninety-Eighth Congress, First session, Washington, D.C., 7 de noviembre.

Van Creveld, M. (1999): The Rise and Decline of the State, Cambridge, Reino Unido, Cambridge University Press. 